\title{
Coordinated Voltage Control in Distribution Network with Renewable Energy Based Distributed Generation
}

\author{
Mohd Khairun Nizam Mohd Sarmin ${ }^{1}$, Worawat Nakawiro ${ }^{1}$, Mohd Zamri Che Wanik², \\ Mohd FadzilMohd Siam¹, ZahrulFaiziHussien", Ahmad Asrul Ibrahim ${ }^{3}$, Ahmad Kamil Mat Hussin ${ }^{2}$ \\ ${ }^{1}$ Smart Grid Section, TNB Research Malaysia, Malaysia \\ ${ }^{2}$ Green Technology Section,TNB Research Malaysia, Malaysia \\ ${ }^{3}$ Power system research group, UniversitiKebangsaan Malaysia, Malaysia \\ Email: mzamri@tnbr.com.my
}

Received 2013

\begin{abstract}
This paper presentsa voltage control strategy for power distribution systems with interconnected renewable energy based distributed generators (DGs). The control strategy coordinating conventional voltage control devices and reactive power from DG.A mixed-integer nonlinear programming problem was formulated and solved by particle swarm optimization (PSO). The code is written using DigSILENT programming language (DPL) and implemented inside DigSILENT power factory simulation software. All system constraints and operating limits are considered. The optimal power flow based approach can incorporate various uncertainties such as intermittent power characteristics and varying load demand. The proposed method is tested using real distribution network to demonstrate its effectiveness. The merits of the proposed method over the classical local-based control are presented in the simulation results. It is demonstrated that the proposed method is capable of keeping the system voltage within operating limit. Power losses is at the same time is minimized in comparison to the losses using conventional method.
\end{abstract}

Keywords: Photovoltaic; Distributed Generation; Particle Swarm Optimisation; DigSILENT; Coordinated Control

\section{Introduction}

Renewable resources has gained significant attention in recent years due to the cost increment and adverse environmental impacts of conventional fossil fuels [1]. Currently, Photovoltaic (PV)energy systems are considered as optimum solution to the electricity supply in most rural zones in developing countries [2,3].

$\mathrm{PV}$ application is gaining a lot of attention in the developing country like Malaysia. Feed in Tariff introduced in Malaysia in 2011 [5] is a sign that the government is serious in promoting PV as a new energy source in supporting Malaysian sustainable growth. Typicallya renewable energy resource such as PV system generateselectricity as distributed generator (DG) is connected to distribution networks. DG application is highlighted offers various benefits to the distribution network where it is connected to but harvesting the benefits is not without challenges [6].

Voltage control is one of well-documented operational challenges [7]. Currently the voltage control strategies are also developed based on the assumption of unidirectional power flow. However in some extreme conditions due to the intermittent and non-dispatchable characteristics the excess DG power could flow in a reverse direc- tion to the transformer high voltage side. Therefore a new scheme for voltage control is definitely needed in modern power distribution systems which comprising DG. Some of these control schemes can be broadly categorized as tabulated in Table 1.

From practical viewpoints, the offline planning approach should be deployed in complimentary with an advanced online controller. This coordination will enable the system to achieve economic operation and guarantee security when subject to unexpected disturbances.

In this paper, an offline (day-ahead) planning approach based on particle swarm optimization (PSO) is proposed. The approach determines optimal settings of all control devices including on-load tap changers, switched shunt capacitors, commonly found in most power distribution network. System state quantities are considered and operational limits is incorporated. PSO code is written in DigSILENT programming language (DPL) and the proposed approach is implemented in DigSILENT Power Factory [15].

\section{Voltage and Reactive Power Control}

The concept of power loses can be explained by referring to Figure 1. In a simple radial network shown in Figure 
1 the voltage drop across the feeder can be approximated by [16-17]:

$$
\Delta U \approx \frac{R \cdot P_{L}+X \cdot\left(Q_{L}-Q_{D G}\right)}{U_{2}}
$$

where $R$ and $X$ are the line resistance and reactance, respectively, and $P$ and $Q$ are the active and reactive power generated from DG. It can be seen that any fluctuation in reactive power will impact the voltage fluctuation. If the constant power factor control is used, the ratio $P / Q$ is maintained. This tends to increase reactive power of DG and thereby aggravating the voltage rise.

When reactive sources available properly compensate the reactive power demand, the feeder current will decrease according to:

$$
I=\frac{\sqrt{P_{L}^{2}+\left(Q_{L}-Q_{D G}\right)^{2}}}{U_{2}}
$$

Therefore the feeder losses $P_{\text {Loss }}$ will also decrease because losses are directly related to current as follow:

$$
P_{\text {Loss }}=I^{2} R
$$

\section{Coordinated Voltage Control}

Figure 2 shows three alternatives for coordinated voltage control (CVC) in a distribution network with DG. The baseline of this scheme is to control the on-load tap changer (OLTC) position of transformer and substation capacitors $C_{S}$ via SCADA as depicted in the red arrow. However if the communication channel is available it

\begin{tabular}{|c|c|c|}
\hline & Offline Planning & Online Control \\
\hline Objective & $\begin{array}{l}\text { Determine optimal } \\
\text { control set points to } \\
\text { achieve min/max objec- } \\
\text { tive(s) whereby main- } \\
\text { taining all constraints } \\
\text { (Optimal Power Flow) }\end{array}$ & $\begin{array}{l}\text { Find the recourse of } \\
\text { controllers to achieve } \\
\text { the target objective (i.e. } \\
\text { to eliminate voltage } \\
\text { violation, line loading, } \\
\text { etc). }\end{array}$ \\
\hline $\begin{array}{l}\text { Time } \\
\text { scale }\end{array}$ & Day-ahead & Online and closed loop \\
\hline $\begin{array}{l}\text { Inputs/ } \\
\text { Data } \\
\text { require- } \\
\text { ments }\end{array}$ & $\begin{array}{l}\text { Offline: Complete } \\
\text { network info, load } \\
\text { forecast, predicted } \\
\text { power generation } \\
\text { (i.e.solar) }\end{array}$ & $\begin{array}{l}\text { Offline: Historical data, } \\
\text { operation rules and } \\
\text { expertise and/or simula- } \\
\text { tion studies. } \\
\text { Online: Selected } \\
\text { measurements }\end{array}$ \\
\hline Example & $\begin{array}{l}\text { Optimization algorithm } \\
\text { - Mathematical pro- } \\
\text { gramming (i.e.[8]) } \\
\text { - Heuristic me- } \\
\text { thods(i.e.[9-10]) }\end{array}$ & $\begin{array}{l}\text { Intelligent system } \\
\text { - Multi agent (i.e.[11]) } \\
\text { - Artificial neural net- } \\
\text { work (i.e.[12]) } \\
\text { - Fuzzy logic } \\
\text { (i.e.[13-14]) }\end{array}$ \\
\hline
\end{tabular}

Table 1. Comparison of distribution network voltage control scheme.

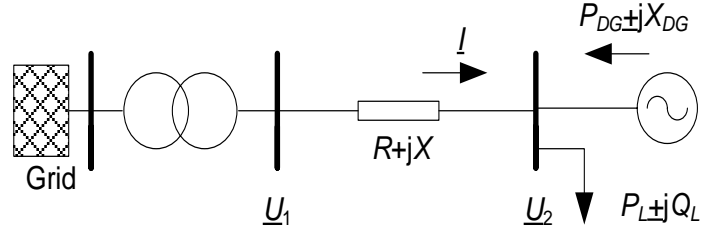

Figure 1. A simple network showing voltage drop.

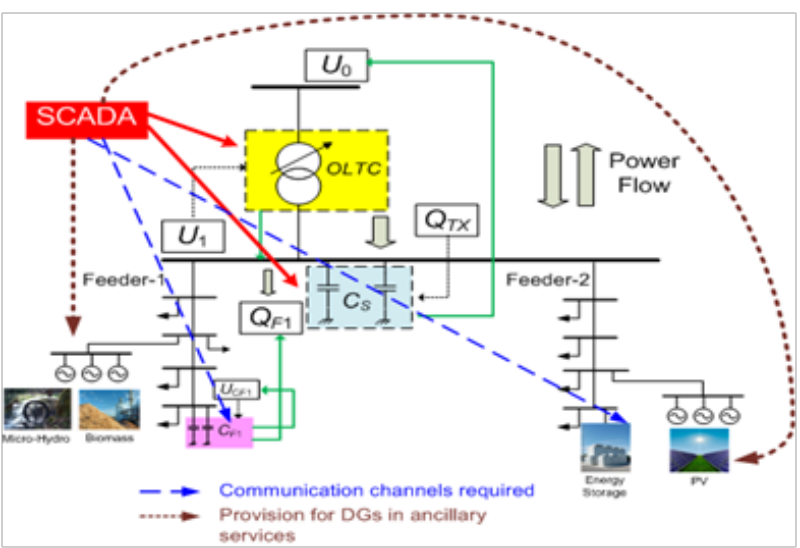

Figure 2. Coordinated voltage control with DG sources.

may be possible to control the capacitors and energy storage devices installed at feeders (see the blue arrows). Moreover if DG can participate in ancillary services, DG reactive power output can also be controlled.

\section{Optimization Formulation}

The optimal coordination of all control devices can be determined by solving the formulated optimal power flow problem. The control variables consist of OLTC position, status of substation capacitors $C s$ and feeder capacitors $C_{F}$ and DG reactive power outputs (continuous variables). The objective can be set to minimize the power loss $P_{\text {loss }}$ as shown:

$$
\text { Min } P_{l o s, t s}=f\left(\mathbf{x}_{t}, \mathbf{u}_{t}, \mathbf{d}_{D, t}, \mathbf{d}_{D G, t}\right) ; \forall t \in T
$$

where all the subscripts trepresents the planning time interval $t$ in the set of all time intervals in a day $T$. The vector $\mathbf{x}_{t}$ represents the state variables as listed in (6)-(9) at time $t$. The vector $\mathbf{u}_{t}$ represents the control variables at time tgiven by:

$$
\mathbf{u}_{t}=\left[\mathbf{T a p}_{t}, \mathbf{C f} \boldsymbol{p} \mathbf{Q v s} \mathbf{s}_{t}, \mathbf{Q g}_{t, i}, \quad{ }_{t, i}\right]
$$

where the subscripts $i$ represent the index of fast (15 minutes; $i=1, \ldots, 4$ ) response controllers. At the consid-

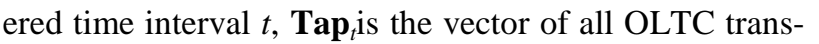
formers; $\mathbf{C f}_{t}$ is the vector of all feeder capacitors; and $\mathbf{C s}_{t}$ is the vector of all feeder capacitors. These discrete controllers have a slow response time (i.e. 1 hour like in this study). On the other hand, the continuous variables have by nature fast response. Therefore, these controls are 
discretized with a smaller time step $i$ (15 minutes; $i=$ $1, \ldots, 4$ for any planning hour $t$ ). At time $t$, the vector $\mathbf{Q g}_{t, i}$ contains reactive power output for all synchronous DGs and the vector $\theta \mathbf{p v}_{t, i}$ contains the power factor set point for all solar PV converter.

The network should be operated within a narrow band of voltage variation to ensure safety of power system equipments and supply quality

$$
U_{\min } \leq U_{i, t} \leq U_{\max }, \forall i \in \mathbf{N}_{\mathbf{B}} \forall t \in \mathbf{T}
$$

where $U_{i, t}$ is the voltage of busi at time $t$; $U_{\min }$ and $U_{\max }$ are minimum and maximum allowable voltages, respectively and $\mathbf{N}_{\mathbf{B}}$ is the set of controlled buses.

The current flow in all lines must be maintained below the rating limit

$$
I_{L, j, t} \leq I_{L, j, \text { rat }}, \forall j \in \mathbf{N}_{\mathbf{L}} \forall t \in \mathbf{T}
$$

where $I_{L, j, t}$ is the current flow on line $\mathrm{j}$ at time $\mathrm{t} ; I_{L, j, \text { rat }}$ is the thermal capacity of line $j$ and $\mathbf{N}_{\mathbf{L}}$ is the set of all lines.

The apparent power transfer on the substation transformer is limited to prevent any overloading

$$
S_{\mathrm{TX}, t} \leq S_{\mathrm{TX}, \mathrm{rat}}, \forall t \in \mathbf{T}
$$

where $S_{\mathrm{TX}, t}$ is the apparent power flow on substation transformer at time $t$ and $\mathrm{S}_{\mathrm{TX} \text {,rat }}$ is the capacity rating of the substation transformer.

When DGs are centrally dispatched, the operating region is restricted by the power factor operating limits described as:

$$
\begin{aligned}
P F_{\text {min }} \leq P F_{k, t} \leq P F_{\text {max }} \Rightarrow \theta_{\text {min }} \leq \theta_{k, t} \leq \theta_{\text {max }} \\
\forall k \in \mathbf{N}_{\mathbf{D G}} \forall t \in \mathbf{T}
\end{aligned}
$$

where $P F_{\text {min }}$ and $P F_{\max }$ are minimum and maximum operating power factor of DGs (here assumed common for all DGs for simplicity), respectively. To consider inductive and capacitive operating range of DGs, the power factor angle $\theta$ is preferred because it is positive for lagging (inductive) and leading (capacitive) power factors. The angle $\theta$ is constrained in the range between the minimum and operating power factor angles $\left[\theta_{\min }, \theta_{\max }\right]$. The $\mathbf{N}_{\text {DG }}$ represents the set of all DGs.

As mentioned earlier that the proposed control methodology will provide the set of optimal control set-points for the day-ahead operation. Therefore the necessary input data is forecast of the load demand and predicted generation pattern to be dispatched for the next 24 hours. The developed optimization algorithm will iteratively search for the best control variables which resulting in the minimum total power losses while maintaining all operational bounds and system security constraints.

The heuristic optimization approach is preferred because of its ability to handle complex problems without any need for an explicit mathematical model. For every iteration, the power system analysis (DigSILENT) is called and load flow simulation is performed to determine the power system states corresponding to the control variables updated by the optimization algorithm. The outputs of this method are the optimal position of transformer tap changers and the optimal status of capacitors for the next day of operation. The explanation given earlier can be depicted as in Figure 3.

\section{PSO Implementation}

PSO algorithm flow chart is depicted in Figure 4. A particle iflies in the search space between two successive iterations according to:

$$
\mathbf{x}_{i}(t+1)=\mathbf{x}_{i}(t)+\mathbf{v}_{i}(t+1)
$$

The original equation for velocity update is given by:

$$
\begin{aligned}
\mathbf{v}_{\mathbf{i}}(t+1)= & \mathbf{v}_{\mathbf{i}}(t)+c_{1} \mathbf{r}_{\mathbf{1}}\left(\mathbf{x}_{\mathbf{p} i}(t)-\mathbf{x}_{\mathbf{i}}(t)\right) \\
& +c_{2} \mathbf{r}_{2}\left(\mathbf{x}_{\mathbf{g}}(t)-\mathbf{x}_{\mathbf{i}}(t)\right)
\end{aligned}
$$

The randomness in the search procedure is introduced by two independent uniform random sequences, $\mathbf{r}_{1}$ and $\mathbf{r}_{2}$ in the range $(0,1)$. The weighting coefficients $c_{1}$ and $c_{2}$ are the acceleration coefficients which control the influence of cognitive and social parameters on the particle's velocity.

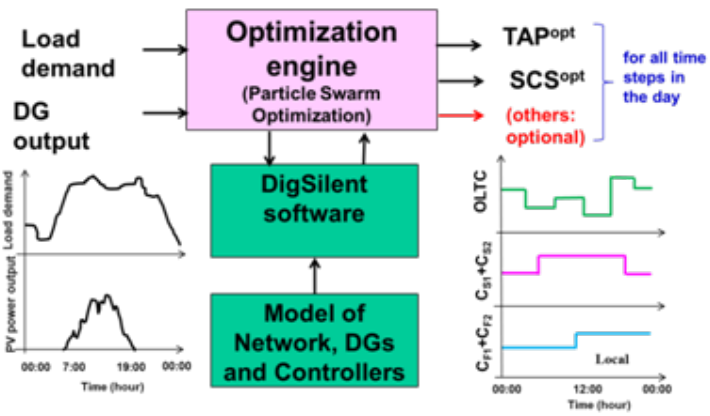

Figure 3. Conceptual diagram of the developed OPF.

\section{PSO Flowchart}

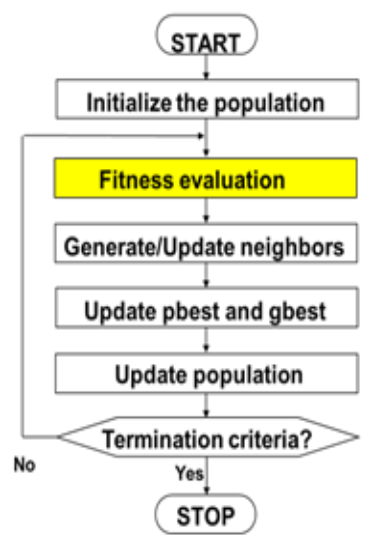

Population: set of candidate solutions (control variables)

Fitness: the quality measure of solution (load flow \& constraint handling)

Learning from its neighbors

Pbest: personal best position Gbest: global best position

$v_{i d}^{k=1}=v_{f d}^{k}+C_{1} r_{1}\left(p_{f d}^{k}-x_{d d}^{k}\right)+c_{2} r_{2}\left(p_{d}^{k}-x_{f d}^{k}\right)$

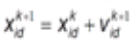

Example:

1. Max no. of iterations

2. No better solution

Figure4. PSO algorithm flow chart. 
In this work, the standard PSO version 2006 was used. The parameters $\mathrm{w}$ and c remain unchanged from [18]. The global best position in the swarm $\mathbf{x}_{\mathbf{g}}$ is considered as $\mathbf{x}_{\mathrm{g}} \in\left\{\mathbf{x}_{\mathbf{p} 1}, \mathbf{x}_{\mathbf{p} 2}, \ldots \ldots . ., \mathbf{x}_{\mathbf{p s}}\right\}$ such that

$$
\mathrm{f}\left(\mathbf{x}_{\mathrm{g}}\right)=\min \left(\mathrm{f}\left(\mathbf{x}_{\mathbf{p} 1}\right), \mathrm{f}\left(\mathbf{x}_{\mathbf{p} 2}\right), \ldots \ldots . ., \mathrm{f}\left(\mathbf{x}_{\mathbf{p s}}\right)\right)
$$

Constraint handling is the most important part in solving a constrained optimization problem. Fitness functions are used to assign a qualitative measure to individuals in the population. To properly handle constraints in PSO, the fitness function should be carefully designed such that it can help guide the swarm process to the promising and feasible search space.

The self-learning penalty function proposed in [19] is applied. The elegant feature of this technique is that it is parameter-less and capable of adjusting the penalized fitness function at different stages of the search process.

\section{Distribution Network}

This section presents the network model used for simulations in this research work. A part of real distribution network in middle region of peninsular Malaysia was chosen as the test network and the schematic diagram is shown in Figure 5. This is a distribution network supplied by two substations. The system basically operates as a radial network with options for feedback from the other 33/11 kV substation in case of breakdown.
Since our assumption is to have high degree of DG penetration, therefore 5x1 MVA synchronous DGs and 5x1 MW solar PV are assumed to be installed at various locations throughout the network. All DGs and solar PVs are connected at $11 \mathrm{kV}$ busbars. The $11 \mathrm{kV}$ busbar is supplied by two 33/11 kV transformers namely $\operatorname{Tr}(\mathrm{L} 1)$ and $\operatorname{Tr}(\mathrm{L} 2)$.

In the simulation, all the loads are assumed to be of constant power type with the power factor of 0.9 inductive. Average power factor was stated to be 0.9. A futureistic load pattern with the peak of 12.8 MW (presently about $5 \mathrm{MW}$ ) is assumed as shown in Figure 6(a). The power output for each solar PV is illustrated in Figure6(b). This data is obtained by fitting the real-measurements from a test unit of $3 \mathrm{~kW}$ solar PV into the normal (Gaussian) distribution. This unit is installed on the rooftop one of the building at UniversitiTenagaNasional main campus.

This assumption may not be accurate since the statistical characteristics of solar energy is quite complicated and varied due to several factors. Finally, the power generation dispatch of synchronous DG is included in the study scope. Therefore, two generation levels are assumed for all synchronous DGs as shown in Figure 6(c). DigSILENT Power Factory [15] is used as the power system analysis software and the PSO code is written in DPL.

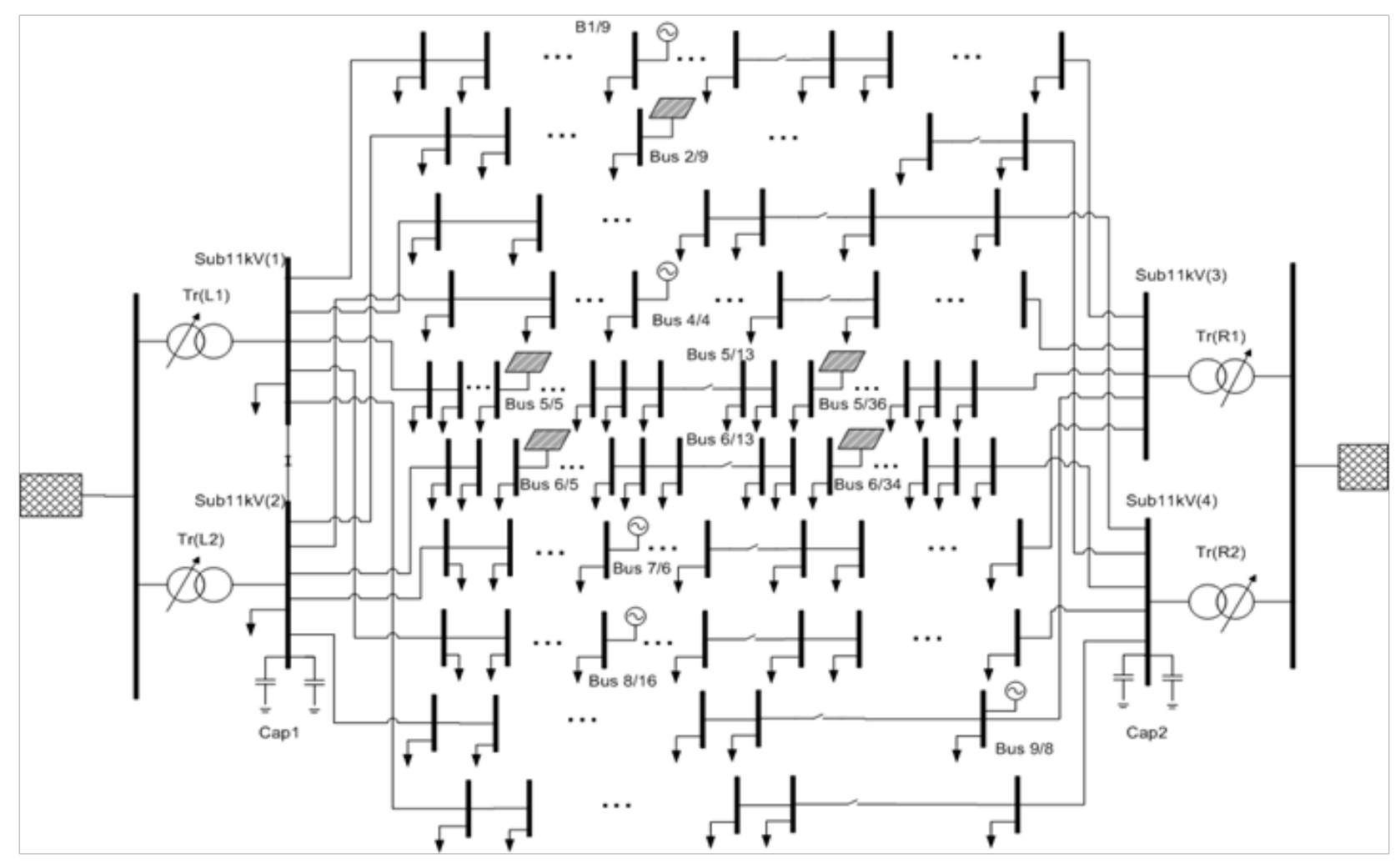

Figure 5. Schematic diagram of the test network. 


\section{Simulation Results}

\subsection{Losses and Cost Comparison}

This section demonstrates the effectiveness of the developed OPF method based on PSO (named 'PSO' hereafter) in comparison with the existing control method based on local information (named 'Local' hereafter). Two cases are considered namely 'noDG' (no DG is connected) and 'withDG' (all DGs and PVs are connected). For the local control method, solar PV and synchronous DG are assumed to operate in the capacitive mode with 0.9 power factor.

Figure 7 displays the total power losses for the daily operation according to the generation and load pattern shown in Figure 6. It is obviously shown that based on the local approach synchronous DGs do not play a role in reducing the losses during the night times. This is because they are not located close to the load center. On the other hand, the solar PV with a fixed power factor control can help reduce losses significantly during day time. This is due to their strategic locations near to load centers in the feeders 5 and 6.

With the PSO approach, it is very clear that the power losses are minimized throughout the day. This is due to the optimal settings of all control variables. The total energy losses (in terms of kWh) of the four cases in Figure $\mathbf{7}$ are calculated as shown in Table $\mathbf{2}$ demonstrates the saving in cost due to energy losses. The energy price is assumed to be RM $0.3 / \mathrm{kWh}$. It can be shown that the savings due to introduction of PSO are $3.06 \%$ in case of no DG and $2.94 \%$ in case with DG.
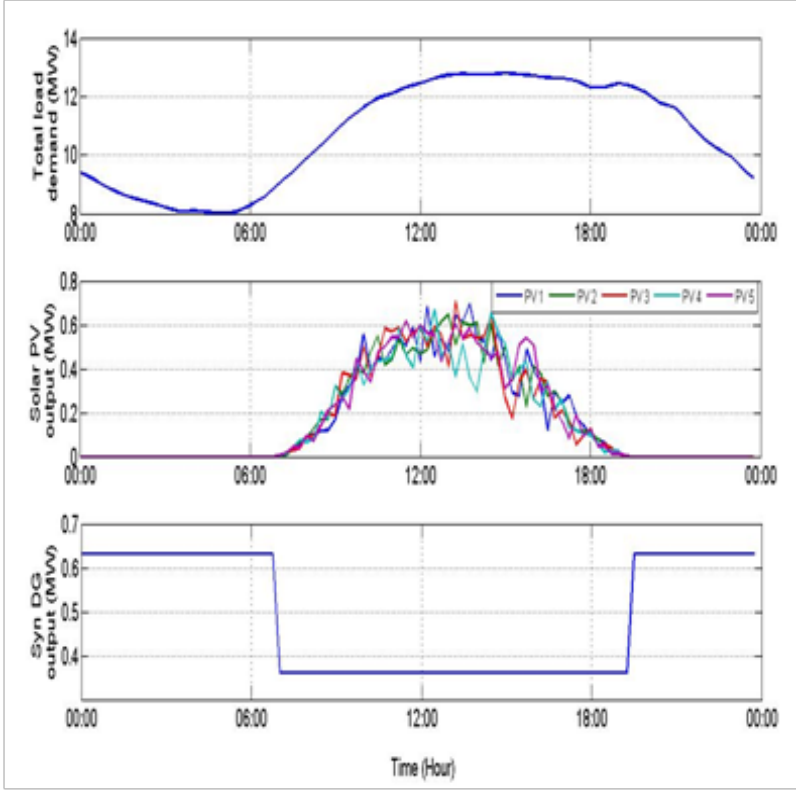

Figure 6. Input data (a) total load demand (b) solar power output of each PV (c) power dispatch of each synchronous DG.

\subsection{Optimal operation}

The optimal setting of all control variables at each time interval is the output of the developed methodology. The optimal tap position for the transformer $\operatorname{Tr}(\mathrm{L} 1)$ is shown in Figure 8. Notice that two changes are required in the local method whereby the total number of tap changes is 11 for the PSO method. This number of change is acceptable in real operational practices for a transformer with similar rating [13]).

\subsection{Voltage Profile}

Voltage magnitudes at the two substations are compared based on the local and PSO methods as shown in Figure 9. It shows that the substation voltages based on the local control method are maintained at a higher level to ensure that voltage at the last bus of all feeders is not below the statutory limit (-5\%). However, the substation voltage in the PSO method is on lower average. This is because the PSO optimizes all available reactive sources in the network and help support voltage at different buses. Moreover the reactive current will be reduced due to the optimal reactive and voltage support. Therefore it reduces the current magnitudes in most feeders and thereby reduces the total power losses.

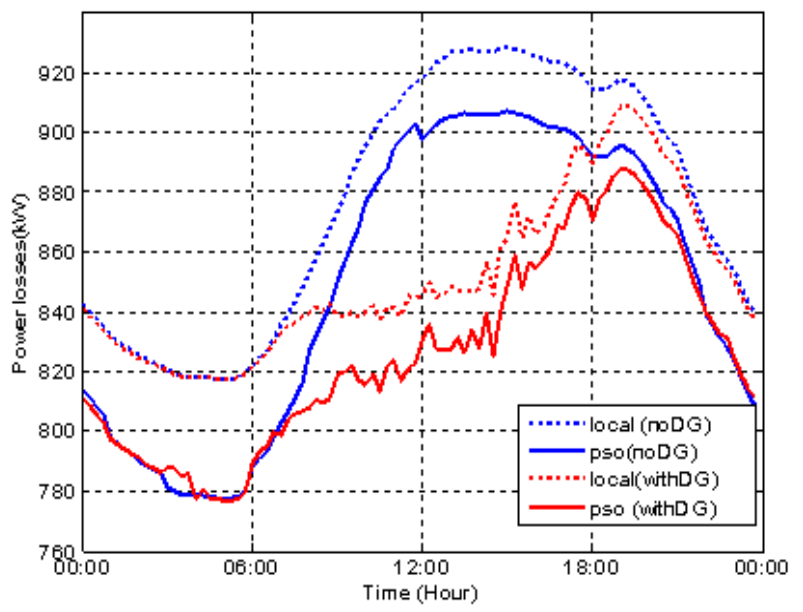

Figure 7. Power losses for a daily operation based on different control strategies.

Table 2. Cost comparison.

\begin{tabular}{ccccc}
\hline Method & $\begin{array}{c}\text { Energy } \\
\text { losses } \\
(\mathrm{kWh})\end{array}$ & $\begin{array}{c}\text { Energy } \\
\text { Cost } \\
(\mathrm{RM} / \mathrm{kWh})\end{array}$ & $\begin{array}{c}\text { Cost of } \\
\text { energy } \\
\text { losses } \\
(\mathrm{RM} / \text { day })\end{array}$ & $\begin{array}{c}\text { Cost } \\
\text { saving } \\
(\%)\end{array}$ \\
\hline local_noDG & 21047.10 & & 6314.13 & \multirow{2}{*}{3.06} \\
pso_noDG & 20402.21 & 0.3 & 6120.66 & \\
local_withDG & 20428.17 & & 6128.45 & 2.94 \\
\hline pso_withDG & 19826.97 & & 5948.09 & \\
\hline
\end{tabular}


Voltage profiles at the last bus of the feeder 5 are shown in Figure 10. It is clear that the voltage level of the PSO method is lower than the local method. This figure also shows possibility of experiencing an under voltage problem when the solar power output highly fluctuates.

\section{Conclusion}

This paper focuses on the offline (day-ahead) planning approach. An optimal power flow (OPF) is formulated to
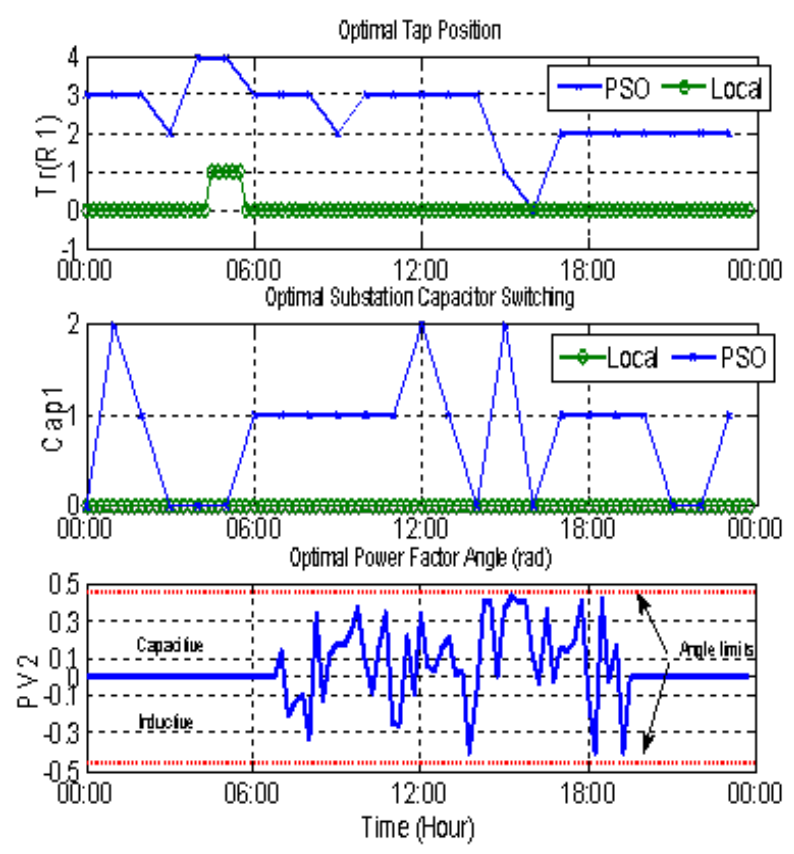

Figure 8. optimal control set points for (a) OLTC transformer (b) substation capacitor(c) solar PV inverter.

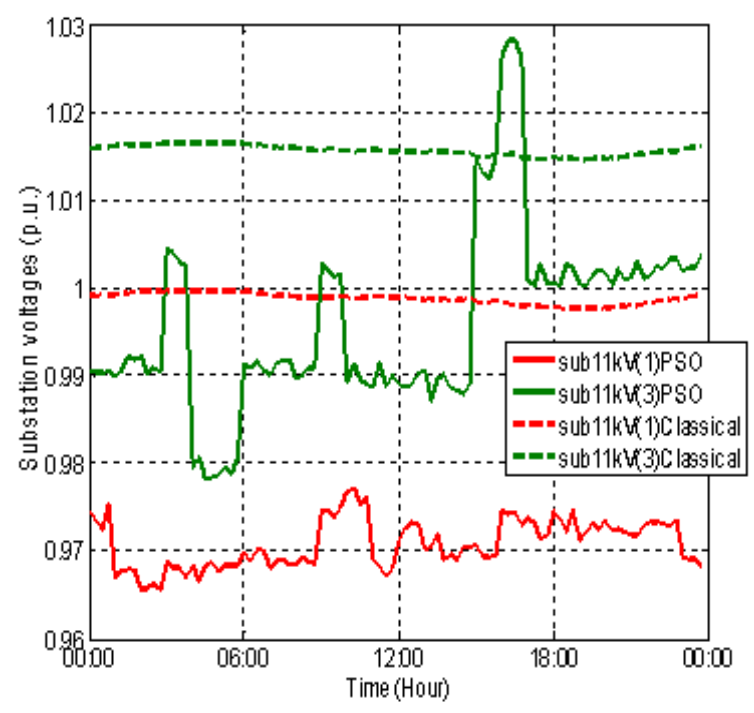

Figure 9. Substation voltages.

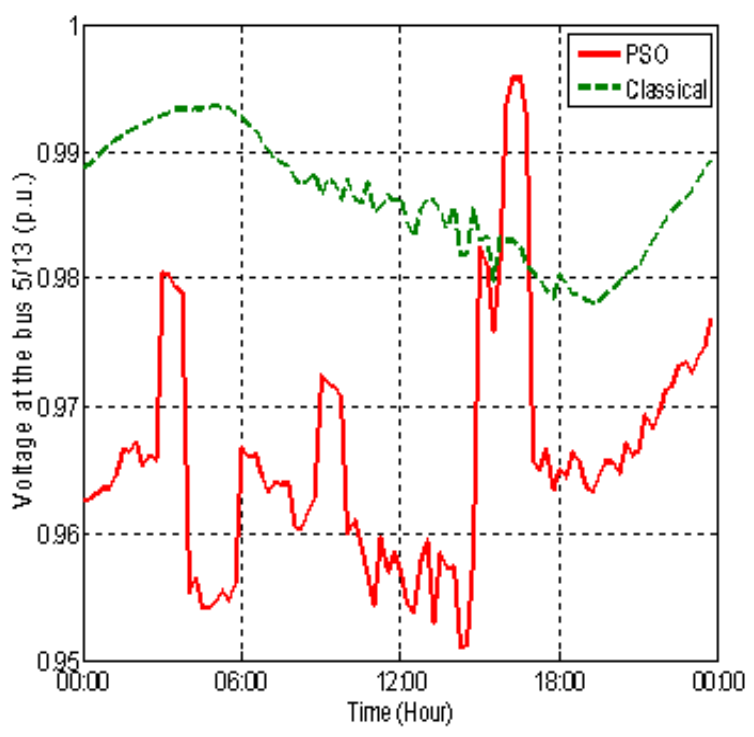

Figure 10. Voltage at one of the feeders.

optimize the desired objectives such by searching for the optimal schedule of all control devices. Power system state quantities are considered and operational limits is incorporated. The optimal power flow based approach can incorporate various uncertainties such as intermittent power characteristics and varying load demand. It is demonstrated that the proposed method is capable of minimizing power losses and voltage deviation in comparison to the conventional method. However the main obstacle for this approach is that it relies on sensors and communication infrastructures which may not be readily available in many power utilities.

\section{Acknowledgement}

This project is funded by TNB Research Malaysia through research funding TNBR/SF 52/2012 and partly supported by UniversitiKebangsaanMalaysia via researchgrant GGPM-2011-071. Dr.-Ing. WorawatNakawiro was a principal researcher at TNB Research Malaysia between Sept 2011 and Aug.2012.

\section{REFERENCES}

[1] T. J. Hammons, J. C. Boyer, S. R. Conners, M. Davies, M. Ellis, M. Fraser, E. A. Holt, and J. Markard, "Renewable energy alternatives for developed countries," IEEE Transactions on Energy Conversion, Vol. 15, No. 4, December 2000, pp. 481-493.

[2] C. Boccaletti, G. Fabbri, J.Marco, and E. Santini, "An Overview on Renewable Energy Technologies for Developing Countries: the case of Guinea Bissau," International Conference on Renewable Energies and Power Quality, Santander, Spain, 2008.

[3] D. N. Nkwetta, M. Smyth, and Vu Van Thong, "Electricity supply, irregularities, and the prospect for 
solar energy and energy sustainability in Sub-Saharan Africa," Journal of renewable and sustainable energy, Vol. 02, 23 March 2010, pp. 16.

[4] Subiyanto, A. Mohamed, and M. Hannan, "Intelligent maximum power point tracking for PV system using Hopfield neural network optimized fuzzy logic controller," Energy and Buildings, Vol. 51, 2012, pp. 29-38.

[5] "Renewable Energy Act 2011, Law of Malaysia, Act 725," 2011. www.seda.gov.my

[6] M. Z. C. Wanik, "Simulation and Management of Distributed Generation: Green Energy Integration to Electrical Power System," Lambert Academic Publishing, Saarbrueken, Germany, 2011.

[7] T. Niknam, A. M. Ranjbar, A.R. Shirani, "Impact of Distributed Generation on Volt/Var Control in Distribution Network," Proceedings of Power Tech Conference of the IEEEPES, Bolongna, 23-26 June 2003, pp. 7.

[8] M. B. Liu, C. A. Canizares and W. Huang, "Reactive Power and Voltage Control in Distribution Systems with Limited Switching Operations", IEEE Transactions on Power Systems, Vol. 24, No. 2, May 2009, pp. 889-899.

[9] Y.-Y. Hong, K.-L. Pen, “Optimal VAR Planning Considering Intermittent Wind Power using Markov Model and Quantum Evolutionary Algorithm," IEEE Transactions on Power Delivery, Vol. 25, No. 4, Oct 2010, pp. 2987-2996.

[10] Y.-Y. Hong and Y.-F. Luo, “Optimal VAR Control Considering Wind Farms using Probabilistic Load Flow and Gray-Based Genetic Algorithms”, IEEE Transactions on Power Delivery, Vol. 24, No. 3, July 2009, pp. 1441-1449.

[11] M.E. Baran and I. M. El-Markabi, “A Multi agent based
Dispatching Scheme for Distributed Generators for Voltage Support on Distribution Feeders”, IEEE Transactions on Power Systems, Vol. 22, No.1, Feb. 2007, pp. 52-59.

[12] G. W. Kim and K. Y. Lee, "Coordination Control of ULTC Transformer and STATCOM based on an Artificial Neural Network," IEEE Transactions on Power Systems, Vol. 20, No.2, May 2005, pp. 580-586.

[13] R.-H. Liang and Y.-S. Wang, "Fuzzy-based Reactive Power and Voltage Control in a Distribution System," IEEE Transactions on Power Delivery, Vol. 18, No. 2, April 2003, pp. 610-618.

[14] D. H. Spatti, I. N. da Silva, W. F. Usida, R. A. Flauzino, "Real-Time Voltage Regulation in Power Distribution using Fuzzy Control”, IEEE Transactions on Power Delivery, Vol. 25, No. 2, April 2010, pp. 1112-1123.

[15] User Mannual, DiGSilent Power Factory v. 14.1, DigSilent GmbH, Gomaringen, Germany, May 2011.

[16] F. A. Viawan, "Voltage Control and Voltage Stability of Power Distribution Systems in the Presence of Distributed Generation”, PhD Thesis, Chalmers University of Technology, Göteborg, Sweden, 2008.

[17] P. N. Vovos, A. E. Kiprakis, A. R. Wallace and P. Harrison, "Centralized and Distributed Voltage Control: Impact on Distributed Generation Penetration”, IEEE Transactions on Power Systems, Vol. 22, No.1, Feb. 2007, pp. 476-483

[18] J. Kennedy and M. Clerc, "Standard PSO 2006," 2006.http://www.particleswarm.info/Programs.html

[19] Biruk Tessema and Gary G. Yen, "A Self Adaptive Penalty Function Based Algorithm for Constrained Optimization,” IEEE Congress on Evolutionary Computation, Oklahoma State University, Stillwater, 2006, pp 246-253. 